DOCTRINA

\title{
El derecho de autor frente a las nuevas tecnologías desde una perspectiva ius privatista y su reflejo actual en el derecho argentino
}

\author{
Copyright and the new technologies analyzed from a private law perspective \\ and its current reflection in Argentinian law
}

\author{
José Pablo Sala Mercado \\ Universidad Bernardo O'Higgins, Chile, y Universidad Nacional de Córdoba, Argentina
}

RESUMEN La sociedad de la información afecta al derecho de autor en diferentes aspectos, tales como nuevas obras protegidas, nuevas formas de explotación de las obras a través de internet, alcance y extensión de los derechos de titulares de obras publicadas en internet y los límites establecidos en beneficio de terceros, alcances y efectos de las infracciones en internet, responsabilidad de terceros intermediarios proveedores de servicios informáticos, etcétera. En el presente trabajo se encontrará el tratamiento jurídico actual de estas cuestiones conforme lo receptan el derecho internacional privado y el régimen doméstico argentino, desde un punto de vista concreto y crítico de la normativa vigente.

PALABRAS CLAVE Derechos de autor, internet, intermediarios, jurisdicción, Argentina.

ABSTRACT The information society affects copyright in different aspects, such as: new protected works, new forms of exploitation of works through the internet, scope and limits of authors' rights that make public their work on the internet, scope and effects of infringements on the internet, responsibility of internet intermediaries, and more. The present work will show the current legal treatment of these issues as provided by private international law and the Argentine domestic law, from a concrete and critical point of view of the current legislation.

KEYWORDS Copyright, internet, intermediaries, jurisdictional competence, Argentina. 


\section{Consideraciones preliminares}

La evolución tecnológica ha penetrado decididamente en todas las ramas del derecho y la propiedad intelectual no ha sido la excepción. Con el avenimiento de esta nueva realidad, que tiene a las computadoras conectadas en red como eje central en torno al cual gira la información en el denominado entorno digital - actualidad cuyas primeras manifestaciones se remontan a fines de la Segunda Guerra Mundial (1945)_, nos encontramos con novedosos objetos protegidos y supuestos fácticos que plantean una serie de interrogantes al momento de aplicar la legislación conflictual y material, ya sea de carácter universal o autónoma.

Por el lado del derecho autoral, cuyo acuerdo universal que goza de mayor consenso es el Convenio de Berna de 1886, se vino en esta nueva era no sólo a incluir los dos nuevos objetos digitales, programas de computación y bases de datos electrónicas, sino también se produjo una afectación en forma transversal a la totalidad de los derechos morales y económicos de que gozan los autores y titulares, respectivamente, con motivo de la llegada de internet.

A lo largo de este trabajo intentaremos no sólo realizar un análisis descriptivo de la actualidad normativa que rige la materia desde la perspectiva argentina, sino también dar cuenta de las falencias de que adolece el citado régimen y que exhortan a su revisión para afrontar la nueva realidad digital. Desde ya adelantamos que, en nuestra opinión, no se trata de un derecho obsoleto que deba ser sustituido, sino que de su actualización parcial llevada a cabo hace algunos años se desprende que no se han brindado respuestas sólidas al entorno digital y ello genera inseguridad tanto para los creadores de obras o sus titulares, como también para los operadores jurídicos y comerciales. Esta premisa rige la estructura del análisis propuesto para contribuir a generar bases compatibles con un deseo de aggiornamento del derecho autónomo argentino, no sólo en lo particular desde el tratamiento ofrecido a los nuevos objetos digitales protegidos (programas de computación y compilaciones de datos), sino también en lo general desde la incidencia clara que internet ha tenido sobre los derechos económicos y morales de la totalidad de las creaciones en resguardo.

\section{Programas de computación y bases de datos}

Respecto a los programas de ordenador, la Organización Mundial de la Propiedad Intelectual (OMPI) los supo definir como «un conjunto de instrucciones expresadas mediante palabras, códigos, planes o cualquier otra forma que, al ser incorporadas en un dispositivo de lectura automatizada, sea capaz de hacer que un ordenador ejecute determinada tarea u obtenga determinado resultado» (Emery, 2014: 53). Asimismo, a los fines prácticos, la doctrina estadounidense lo define como todo programa diseñado con el fin de que una computadora cumpla con una determinada función (Simensky y Bryer, 1994: 81). 
En cuanto a recepción legislativa de estas obras, su resguardo por el derecho de autor tuvo como primera iniciativa la Copyright Act de los Estados Unidos (1980), incluida en el título 17 del US Code. Mediante el dictado de esta normativa se incluye por primera vez como obra protegida a estos objetos digitales bajo el amparo del derecho autoral. Asimismo, esta concepción protectora del sistema jurídico estadounidense vio su espejo en el otro gran modelo regulador, el derecho europeo, que a través del dictado de la Directiva 91/250/CEE, en 1991, brindó protección semejante.

Los dos modelos vanguardistas en la materia ya habían incluido al software como obra intelectual, pero todavía restaba que ello se expandiera al resto de los países de la comunidad internacional a fin de garantizar la creatividad y la inversión como presupuestos necesarios de existencia de esos objetos protegidos.

La discusión en materia de los programas de computador, en resumidas cuentas, se sostuvo en relación a su naturaleza diferenciada con el resto de las obras autorales, puesto que los primeros resultan absolutamente utilitarios mientras que las últimas, obras tradicionales, persiguen la gratificación del espíritu al sólo efecto contemplativo (Gómez Perals, 1999: 156). Lo referido llevó a un planteo de alternativas respecto de la protección del software, ya sea mediante una protección fuera del derecho de autor, o dentro de este derecho como una obra asimilable al resto o, finalmente, como una obra autoral con tratamiento diferenciado.

Fue en el año 1994, con la culminación de la denominada Ronda Uruguay, en el marco de la Organización Mundial del Comercio (OMC), el momento en que se puso fin al debate mediante la suscripción de los Acuerdos sobre los Aspectos de los Derechos de Propiedad Intelectual relacionados con el Comercio (ADPIC en español y TRIPS en inglés), por cuanto el artículo décimo del instrumento concedió protección al software en forma idéntica que la establecida para las obras literarias por el Convenio de Berna. El resguardo opera tanto para la versión fuente, comprensible por las personas, cuanto para la versión objeto, comprensible por los computadores.

En cuanto a las bases de datos, estas obras sufrieron la transformación fruto de la era digital, pero su protección no se vio afectada, sino ratificada aún bajo este nuevo formato, aplicándole el mismo resguardo otorgado por el Convenio de Berna en su artículo 2, inciso quinto. El artículo décimo del ADPIC, en su segunda parte, materializa esta referencia.

\section{Internet y la World Wide Web}

Internet, como red informática mundial, ha venido a producir una revolución en el tráfico legal e ilegal de las obras autorales digitalizadas, puesto que este modo comunicacional no sólo afecta en forma transversal a los derechos de autor, sino que también ha provocado un necesario replanteo de los conceptos hasta ahora utilizados. 
La nueva era digital no sólo incide sobre los derechos morales correspondientes a los autores, o económicos correspondientes a los titulares, sino que también repercute considerablemente sobre los derechos reconocidos a terceros como límite a los derechos de autor y que actualmente se encuentran en el centro del debate universal.

Con motivo de esta novedosa realidad y como primera manifestación, en el año 1996 se suscribieron el Tratado de la OMPI sobre Derechos de Autor (TODA) y el Tratado de la OMPI sobre Interpretación o Ejecución y Fonogramas (TOEIF), denominados «Tratados Internet» de la OMPI, acuerdos que buscaron la adaptación del Convenio de Berna al entorno digital, y reconocieron no sólo los objetos digitales (artículos 4 y 5 de TODA), sino también el entorno en red.

Por su naturaleza, internet nos ha planteado alcances y efectos insospechados para la normativa que rige con antelación a este fenómeno, cuestiones que han desembocado en la necesidad de imponer mediante los tratados algunas medidas de minimis con el fin de brindar respuestas reglamentarias de la nueva realidad, sin perjuicio de que los Estados contratantes asuman el compromiso de avanzar en la regulación particular de los institutos reconocidos.

Con el mismo propósito regulador, pero con ánimo de avanzar sobre materias no revisadas o precariamente reguladas, se intentó acordar el Acuerdo Comercial Anti Falsificación por algunos Estados, ${ }^{1}$ acuerdo que finalmente no vio la luz.

Realizada una breve reseña de la realidad universal en términos de acuerdos vigentes y la nueva realidad que pretenden receptar, corresponde ingresar en el tratamiento de los institutos jurídicos que materializan el cambio en el derecho autoral con motivo de los avances tecnológicos.

\section{Realidad argentina de fuente convencional y autónoma}

La República Argentina es signataria de los convenios hasta aquí referidos, esto es: Convenio de Berna, ADPIC, y los Acuerdos Internet de la OMPI.

Los convenios de cualquier índole, bilateral o multilateral, han sido objeto de la reforma constitucional del año 1994, acto constituyente por el cual los acuerdos con potencias extranjeras adquieren la categoría de supralegales y, para el caso de los tratados de derechos humanos, jerarquía constitucional.

La nueva sistematización piramidal del derecho nacional vuelve de aplicación directa las normas convencionales, primando estas últimas disposiciones por encima de aquellas reglas de fuente autónoma para el caso de conflicto en sus disposiciones. De esta manera, nuestro país presenta un sistema jurídico confiable desde la perspectiva internacional, y se debe destacar a este respecto que, previo a la reforma, las

1. Participaron de las negociaciones en sus diferentes etapas: Australia, Canadá, la Unión europea, Japón, la República de Corea, México, Marruecos, Nueva Zelanda, Singapur, Suiza y Estados Unidos. 
normas comprendidas en los tratados internacionales revestían igual jerarquía que sus pares de carácter interno, lo que implicaba que mediante el dictado de legislación nacional se podía modificar lo dispuesto por aquéllas conforme los principios de especialidad o temporalidad.

De esta manera, el derecho interno debió adaptarse a los compromisos internacionales asumidos por el Estado argentino, situación que en la propiedad intelectual provocó una reforma parcial de la normativa doméstica y que seguidamente analizaremos. Vale decir, en este respecto, que si bien en nuestra opinión los tratados resultan operativos en forma directa conforme se desprende de la carta magna argentina (artículo 75, inciso vigesimosegundo, Constitución Nacional), es dable distinguir el alcance práctico de los mismos. Los acuerdos internacionales vinculan a Estados provenientes de diferentes familias jurídicas, de allí la difícil tarea de alcanzar una armonización total en la regulación. Pese a ello, lo cierto es que las normas internacionales siembran un estado de mínima o punto de partida regulatorio en aras de proponer una uniformidad de base y respecto de la cual deberán avanzar los miembros individualmente en su derecho interno, todo según sus propias necesidades. También, la necesidad de reglamentación no surge sólo de ampliar la protección a los institutos receptados mediante normas materiales por los tratados y que decididamente son operativas, sino también por la delegación que otros preceptos han formulado para que los miembros decidan sobre la introducción o no de ciertas regulaciones. En el caso argentino, la Ley 11.723 debió actualizarse al menos parcialmente para guardar coherencia con los compromisos internacionales asumidos y que tienen rango supralegal. ${ }^{2}$

\section{Nuevos conceptos: Los derechos de reproducción y de comunicación pública en el mundo digital}

La nueva era tecnológica vino a plantear la necesidad de redefinir algunos conceptos; entre ellos, los derechos patrimoniales de reproducción y de comunicación pública. Fue así como dentro del primero podemos referir a las reproducciones efímeras o temporales que ocurren en el ámbito de internet, actos que quedan comprendidos dentro del concepto amplio de reproducción y que necesariamente precisan la autorización del titular de los derechos económicos. En otro orden, respecto del derecho de comunicación pública, los Tratados Internet de la OMPI a los que referiremos seguidamente y que fueron suscritos por Argentina, han introducido la variable de la puesta a disposición de las obras mediante la modalidad a demanda o a la carta del usuario, todo lo cual implica la ausencia de coexistencia en tiempo y espacio entre el usuario y la comunicación, ya que aquél puede acceder a la obra desde el lugar en que se encuentre y en el momento en que lo deseare.

2. Modificación por Ley 25.036 del año 1998. 


\section{Las reproducciones efímeras y temporales}

Para el caso de la ley argentina, en consonancia con lo que dispone el artículo noveno del Convenio de Berna, el titular o autor, según el caso, tiene el derecho de autorizar la reproducción por cualquier procedimiento y bajo cualquier forma (artículo 2 de LPI). De esta manera, el derecho de explotación exclusiva que corresponde al autor o titular se manifiesta en su doble faceta, positiva y negativa, esto es, para la explotación propia de la obra en forma monopólica y para negarse a que cualquier tercero la explote sin autorización.

Ahora bien, más allá de la disposición legal que por su redacción parece significar una barrera a todo tipo de reproducción, lo cierto es que en la red se producen un sinnúmero de reproducciones que no acarrean consecuencia patrimonial ni perjuicio alguno para el autor. Vale decir, un supuesto es el de la reproducción final de la obra que permite el acceso o la consulta por el usuario, y otra bien diferente son aquellas reproducciones intermedias o efímeras que no contienen un fin en sí mismas ni tampoco un significado económico, sino que forman parte de un proceso que culmina en la reproducción final. Así las cosas, entendemos que para estas últimas no está exigida la necesaria autorización previa. Esta restricción del derecho autoral o del titular responde a dos criterios fundamentales, a saber:

- La reproducción intermedia y efímera superaría parcialmente el examen de los tres pasos que reconocen los tres tratados internacionales aquí referidos (Convenio de Berna, ADPIC y Tratados Internet) y de los cuales Argentina es signataria, puesto que no se ofende el legítimo interés del autor ni se afecta la normal explotación de la obra (artículo 9, inciso segundo del Convenio de Berma; artículo 13 de ADPIC y artículo 10 de TODA). La cuestión radica en que, más allá de la compatibilidad con estos dos presupuestos, la superación parcial se debe a la ausencia del tercer elemento, ya que, para dar cabal cumplimiento al examen de los tres pasos, Argentina debió introducir la excepción dentro de su sistema tasado de excepciones. Ello se debe a que, para superar totalmente el examen, el límite al derecho del titular establecido en beneficio de terceros debe encontrarse receptado expresamente en el derecho autónomo, lo que no ocurre en el caso argentino. Vale decir, que modalidad de sistema cerrado de excepciones a la que adscribe Argentina es el denominador común de los países emparentados con el derecho continental europeo y que difiere de la utilizada por los países del Common Law, ya que estos últimos, mediante la excepción del fair use, han introducido una excepción abierta y de valoración a posteriori.

- Aun no tratándose de un fin pedagógico, no puede objetarse que se trataría de un acto legitimado en la medida del fin perseguido y que constituiría, al menos 
por su naturaleza, un uso honrado en los términos del artículo décimo, incisos primero y segundo del Convenio de Berna, sin perjuicio de que este uso como límite fronterizo de las excepciones no fue previsto para las puntualmente descritas en el tratado (derechos de cita y excepciones educativas). Es por todo ello que, entendemos, debe receptarse la excepción, ya que actualmente y conforme lo referido en el párrafo anterior, estos tipos de reproducciones se encuentran prohibidas al no encontrarse previstas.

\section{Internet y la copia privada digital}

La copia privada, aquélla realizada en un ámbito íntimo que no ofende el legítimo interés del autor ni afecta la normal comercialización de la obra, tiene especial importancia en la era de la información.

Sucede que la copia digital, a diferencia de la física, resulta de la misma calidad que el original, se realiza en forma inmediata produciendo infinidad de ejemplares y por red puede distribuirse con alcances insospechados en cuestión de segundos, por lo que puede ocasionar un daño irreversible al titular de los derechos de explotación. Vale decir, que internet ha venido a incidir significativamente respecto de esta limitación a los derechos de autor y titulares, con lo que ha vuelto a estos últimos más vulnerables y expuestos a menoscabos mayúsculos.

Ahora bien, en la mayoría de los sistemas, incluyendo el argentino, la limitación a los derechos de autor o titular de un programa de computador no incluyen la copia privada, sino de seguridad o salvaguardia. Es así que el adquirente legítimo de un software sólo puede realizar una copia que tendrá como resguardo ante la posibilidad de que el computador o el programa allí instalado presenten fallas que lo inutilicen (González de Alaiza Cardona, 2008: 55). Sólo allí se podrá utilizar la copia de seguridad para reinstalarlo y posibilitar su uso (artículo 9 de LPI). Vale decir, que el destino de la copia se encuentra absolutamente delimitado y su observancia garantiza el uso legítimo de la misma por parte del usuario.

\section{El derecho de comunicación pública}

En otro orden, siguiendo con el análisis propuesto, es dable destacar también la extensión del derecho de comunicación pública que hoy abarca la modalidad de puesta a disposición de la obra a demanda del usuario, mecanismo por el que se puede acceder a la misma desde cualquier momento y lugar en el que el usuario así lo deseare (artículo 8 de TODA). Es decir, que ya no necesariamente coinciden en tiempo y lugar la reproducción o representación de la obra y el público, sino que aquélla se encuentra alojada en una plataforma digital accesible por el usuario desde cualquier sitio y que le posibilita reproducirla en cualquier momento. La novedad reside en la 
puesta a voluntad del usuario y falta de coincidencia temporal, ambos elementos que no se encontraban en otros mecanismos de comunicación a distancia como la radio o televisión, mas vale aclarar que la sola puesta a disposición no equivale a un acto de comunicación (Goldstein, 2005: 289). Se trata de un efecto diferido al que se encuentra sujeta la consumación del acto voluntario de comunicación autorizado por el autor o titular.

Este nuevo modo de comunicación, asimismo, reabre el debate que se sostuvo con la llegada de las retransmisiones por cable en relación con el agotamiento de los derechos del titular, pero ahora se centra sobre las obras publicadas en red. Pues bien, vale acogerse, como lo ha hecho la doctrina moderna en su momento respecto de las retransmisiones por cable, a la teoría amplia del agotamiento del derecho de emisión, según la cual este derecho, como tal, no se agota (Erdozain López, 1997: 59).

Finalmente, debe aclararse que existe discusión respecto a si la puesta a disposición a demanda del usuario reviste el carácter de un derecho autónomo del titular o si, por el contrario, se trata de una modalidad subsumida dentro del derecho de comunicación pública. A este respecto, y conforme los términos sistemáticos que ofrece el tratado de derecho de autor de 1996 en su artículo octavo, entendemos corresponde alinearse con la segunda postura.

\section{Internet: Lugar de publicación como criterio de protección}

El Convenio de Berna reconoce tres criterios de protección: nacionalidad, residencia y lugar de publicación. Los dos primeros no presentan una conexión inmediata con la obra, cuestión que no ocurre con el tercero, que sí presenta un vínculo directo y se condice con la voluntad del autor de exhibir la obra en tierras de mayor protección (artículo 3).

En cuanto a los criterios de nacionalidad y residencia, no existe modificación alguna, pero no ocurre lo mismo respecto del lugar de publicación con la llegada de internet. Los interrogantes más considerables residen sobre la consideración y extensión que debe darse a una publicación en internet. Éstos son: ¿cuál sería el lugar de publicación? ¿Se trataría de una publicación universal?

Estos interrogantes no son resueltos por los Tratados Internet de la OMPI que datan de más de veinte años de suscripción, por lo que debemos analizar la naturaleza del acto publicitario y diferenciarla del acceso que a él se tenga.

Así las cosas, nos parece propio decir que por el advenimiento de internet no ha cesado la naturaleza del acto de publicar la obra en un lugar determinado, sino que la modificación se produce respecto del alcance de esa publicación en relación con el acceso que a la misma se tenga. Vale decir, como venimos diciendo en otros textos (Sala Mercado, 2017), que la publicación no es universal, aunque el acceso sí lo sea. Para determinar el lugar de publicación hay que atender al servidor utilizado para co- 
nectarse a la red, ya que no es más que el canal de acceso necesario para llevar a cabo el acto y es fácilmente determinable. Es el servidor utilizado para la carga (upload) de la obra el que define el lugar de publicación.

Luego, también se puede atender a los destinatarios a los que está dirigida la publicación según el sitio de internet donde se formule considerando las características del mismo y valorando elementos tales como: idioma, domicilio del sitio, dominio de internet, etcétera. Incluso, en coherencia con lo referido, es sabido que el acceso puede limitarse luego por los proveedores de servicios de internet o por los motores de búsqueda, por lo que no es la materia relevante tenerlos presente para esta determinación. Internet tiene fronteras del mismo modo que las tienen los países. Si no, no se explica que ciertos países prohíban a los usuarios el acceso a portales determinados. ${ }^{3}$

\section{La adaptación o transformación para uso personal del software legítimamente adquirido}

La imposibilidad de obtener una copia privada de un programa de computador, obra para la cual el límite a los derechos de autor o titular reside en la constitución de una copia de seguridad o salvaguardia en la mayoría de los sistemas jurídicos, nos lleva a plantearnos si la prohibición de reproducción con la excepción descrita se extiende también a la posibilidad de adaptación del software adquirido o del que se detenta una mera tenencia a consecuencia de un contrato de licencia de uso.

Vale decir, que el límite al derecho de reproducción de un programa de computador reside en la posibilidad de generar una sola copia de seguridad por parte del adquirente o usuario y al sólo efecto de sustituir el programa original ante la eventualidad de que se afecte su funcionamiento o el del computador en que se ha descargado (artículo 9 de LPI).

Sin perjuicio de ello, entendemos que distinto es el caso de la adaptación del programa de computador que pudiera realizar el adquirente, por cuanto estas obras presentan un carácter meramente utilitario, no contemplativo, y el comprador de este objeto digital puede mejorarlo para sólo provecho personal, sin que se comercialice la versión resultante. Los derechos morales, entre los que se comprende al de conservar la obra en cuanto a su integridad o preservar su incolumidad, se encuentran absolutamente mermados en los programas de computación por la naturaleza de obra de que se trata.

En este orden, si un adquirente mejora en su intimidad la producción del programa o magnifica el alcance de los resultados propuestos por la obra, incluso resultados nuevos no buscados, en nada afecta los legítimos intereses del autor y la normal explotación de la obra (artículos 13 de ADPIC y 10 de TODA). Más aún, podría considerarse dicho uso como honrado bajo la terminología empleada en la Convención de

3. Véanse los ejemplos de China, Corea del Norte, Venezuela, Cuba y otros. 
Berna (artículo 10). Se trata de un supuesto en donde ya se produjo el agotamiento del derecho de exclusiva respecto del ejemplar vendido por parte del titular y no hay un uso comercial de la obra adaptada, por lo que resulta claro que no se vulnera el examen de los tres pasos. Sin perjuicio de ello y, como ya se expresará, actualmente actos como el referido se encuentran prohibidos al no encontrarse receptados expresamente como excepción, condición necesaria para la observancia del examen de los tres pasos. En consecuencia, entendemos es necesaria una disposición que disponga su recepción para poner fin a este debate.

No se trata de volcarnos al supuesto del software libre que pretende mediante su manipulación por la comunidad digital lograr una mejora continua y el anhelado aprovechamiento plural, sino que referimos a este único y específico caso del adquirente que pretende modificar esa obra resultadista para sí y para alcanzar un mejor resultado. Creemos que estos actos son lícitos, sin perder de vista que para su consecución será necesaria previamente la ingeniería inversa, conocida como el examen funcional de las ideas y fundamentos del programa de computador con el fin de comprobar con precisión sus elementos. Argentina no regula este proceso, pero hay otros sistemas que sí lo hacen y pueden servir como fuente de inspiración.

En el derecho comparado, encontramos el Texto Refundido del Real Decreto Legislativo español (TRLPI 1/1996), que con buen lápiz propone: a) la admisión de la adaptación o transformación sin autorización del titular cuando, adquirido lícitamente un programa de computación, éste no fuese compatible con el sistema operativo que utiliza el usuario y se hicieren transformaciones y adaptaciones para garantizar la interoperabilidad; b) la reproducción o transformación, incluida la corrección de errores, que resulten necesarias para su utilización por parte del usuario legítimo con arreglo a su finalidad propuesta; c) no podrá oponerse el autor a que el cesionario realice o autorice la realización de versiones sucesivas de su programa ni de programas derivados del mismo, salvo pacto en contra; y, finalmente, d) la descompilación e interoperabilidad: el usuario legítimo podrá realizar en él los actos de reproducción y transformación que sean indispensables para obtener la interoperabilidad del programa en relación con determinadas situaciones, límites y objetivos. Los supuestos de descompilación no podrán ser interpretados de manera que su aplicación perjudique de forma injustificada los legítimos intereses del titular de los derechos (artículo 100 de TRLPI). El usuario legítimo es todo aquél que tiene derecho a utilizar el programa, cualquiera sea la causa fuente de ese derecho: alquiler, préstamo o adquisición en propiedad (Rodríguez Tapia y Bondía Román, 1997: 378).

Es dable destacar que la primera venta en la Unión Europea de una copia de un programa por el titular de los derechos o con su consentimiento, agotará el derecho de distribución de dicha copia, salvo la facultad de controlar el subsiguiente alquiler del programa o de una copia del mismo, todo lo que fundamenta este tratamiento particular (artículo 99 inciso c de TRLPI). 


\section{La responsabilidad de los intermediarios en internet y medidas de tutela de los derechos de autor}

Otra cuestión que ha tomado relevancia en el último tiempo ha sido la adjudicación de responsabilidad a los intermediarios, sean éstos servidores de red o de alojamiento de datos, $\mathrm{o}$ incluso de motores de búsqueda, por el contenido de publicaciones infractoras del derecho autoral.

Ante la actuación de intermediarios en internet que generan consecuencias con alcances impensados, resultan de vital tratamiento las medidas procesales viables para impedir, o bien el daño, o bien que una vez producido el mismo no se mantenga en el tiempo y así acotar su extensión.

La aceleración de los cambios históricos, el avance científico y tecnológico y el aumento de las necesidades espirituales y materiales, a lo que se adiciona la revolución de las comunicaciones, requieren del ámbito jurisdiccional una perspectiva dinámica en correspondencia con los sistemas de comunicación, el crecimiento exponencial de la tecnología y su gravitación sobre la mentalidad, las actividades y los comportamientos individuales y sociales. ${ }^{4}$

\section{Responsabilidad de los motores de búsqueda en internet ${ }^{5}$}

Una temática de total actualidad en el ámbito local e internacional es la responsabilidad de los buscadores o motores de búsqueda en internet por infracción a los derechos de imagen. La responsabilidad resulta de la función de intermediarios, sin los cuales dichas infracciones no podrían cometerse o, de hacerlo, serían de efecto reducido. Asimismo, la controversia se plantea en términos de asegurar la libertad de expresión y garantizar el respeto por los derechos individuales.

La OCDE define a los intermediarios de internet como «aquéllos que prestan o facilitan el intercambio y las transacciones entre terceros, tratan de dar acceso al host, indexar contenido de productos y servicios originados por terceros en internet o proporcionan servicios basados» (CICOMRA, 2016). Por su parte, la doctrina comparada ha señalado que al explorar internet de manera automatizada, constante y sistemática en busca de la información que allí se publica, el gestor de un motor de búsqueda «recoge» tales datos que «extrae», «registra»y «organiza» posteriormente en el marco de sus programas de indexación, «conserva» en sus servidores y, en su caso, «comunica» $\mathrm{y}$ «facilita el acceso» a sus usuarios en forma de listas de resultados

4. Sagües Guillermo Ernesto y otro con Google Inc. y otro s/ daños y perjuicios, Cámara Nacional de Apelaciones en lo Civil y Comercial Federal de Argentina, sala 3, 13 de mayo de 2015.

5. Véase José Pablo Sala Mercado, «Responsabilidad de los intermediarios en internet: Breve análisis de la actualidad en la Argentina», Microjuris, 15 de noviembre de 2016, disponible en http://bit.ly/2CcIJ1C. 
de sus búsquedas. ${ }^{6}$ Internet permite la maximización de los efectos y la participación, en ese sentido, de los buscadores no es menor.

Diversos han sido los criterios adoptados por los tribunales argentinos, pero nos adelantamos en admitir que, a nuestro entender, no existen normas que regulen expresamente esta cuestión y, asimismo, la aplicación indiscriminada de la teoría general de responsabilidad civil puede traer consecuencias no valiosas. ${ }^{7}$ Se ha dicho que

el rol de los buscadores es facilitar a sus usuarios el acceso a páginas de internet (algoritmos de búsqueda que operan en forma automática) [...], pero quien o quienes deciden el contenido que se carga en cada sitio web, es precisamente cada sitio... La justificación de la responsabilidad extracontractual (deber de resarcir el daño) se pone en la violación de que, quien atenta contra el círculo jurídico (de ordinario patrimonial) ajeno, ocasionándole un daño, está obligado a eliminarlo... Quien pretenda el resarcimiento deberá demostrar la culpa o negligencia en que incurrió el buscador conforme al régimen general de responsabilidad por el hecho propio con anterioridad a cualquier reclamo del afectado solicitando el bloqueo del contenido que considera agraviante y disponible en internet a través de los buscadores demandados, no puede a los mismos serle atribuida o adjudicada culpa alguna por los contenidos cuestionados. ${ }^{8}$

Las distintas posturas que asume la jurisprudencia nacional denotan, quizás, un norte incierto en la materia, partiendo de la resolución más resonante que ha dictado nuestro máximo tribunal en el año 2014, solución que fue adoptada por estricta mayoría y hoy podría variar si se tiene en cuenta que se ha modificado la integración de ese alto cuerpo judicial. ${ }^{9}$ En esa resolución, la Corte, con el voto de la mayoría (doctores Highton de Nolasco, Fayt y Zaffaroni), estableció que internet era una vía por la que se concretiza el derecho personal de libertad de expresión que tiene todo individuo y que es comprensivo de hacer público, transmitir, difundir y exteriorizar -o no hacerlo- sus ideas, opiniones, creencias, críticas, etcetera, permitiendo así que miles de millones de personas en todo el mundo expresen sus opiniones, a la vez que incrementa significativamente su capacidad de acceder a la información y

6. Sentencia de Google Spain, S.L. y Google Inc. con Agencia Española de Protección de Datos (AEPD) y Mario Costeja González, Tribunal de Justicia de la Unión Europea, 13 de mayo de 2014.

7. N. E. F. con Facebook Argentina S. R. L. s/ medida autosatisfactiva, Juzgado Federal de Río Cuarto, septiembre de 2013 .

8. Da Cunha Virginia con Yahoo de Argentina SRL y otro s/ daños y perjuicios, Cámara Nacional de Apelaciones en lo Civil y Comercial Federal de Argentina, sala D, 2010. Lorenzo, Bárbara con Google Inc. s/ daños y perjuicios, Ordinario Cámara Nacional de Apelaciones en lo Civil y Comercial Federal de Argentina, sala 1, 2016.

9. María Belen Rodriguez con Google Inc s/ daños y perjuicios, Corte Suprema de Justicia de la Nación Argentina, 28 de octubre de 2014. 
fomenta el pluralismo. Por su parte, en cuanto a los límites de esa libertad, el Supremo sostiene que en ausencia de una regulación legal específica, conviene sentar una regla que distinga nítidamente los casos en que el daño es manifiesto y grosero, a diferencia de otros en que es opinable, dudoso o exige un esclarecimiento (pornografía infantil, datos que faciliten la comisión de delitos o pongan en peligro la vida, discriminación con manifiesta perversidad o incitación a la violencia o apología del genocidio o racismo), pero en los casos que exijan un esclarecimiento o deban debatirse o precisarse en sede judicial o administrativa para su efectiva determinación, cabe entender que no puede exigirse al buscador que supla la función de la autoridad competente, ya que los buscadores no tienen la obligación general de monitorear los contenidos que se suben a la red y que son proveídos por los responsables de cada una de las páginas de la red. Los buscadores no pueden ser condenados por lo que no han creado.

En otro orden, la minoría (doctores Maqueda y Lorenzetti) ${ }^{10}$ sostuvo que debe acreditarse la culpa del buscador, ya que existe un comportamiento antijurídico cuando es puesto en conocimiento del daño y no adopta medidas para erradicarlo. A este respecto, deben implementarse los sistemas de aviso previo que consisten en la posibilidad de solicitar la eliminación o bloqueo de enlaces que resulten claramente lesivos de derechos personalísimos y también reclamar que, de acuerdo con la tecnología disponible, los buscadores adopten las medidas necesarias para prevenir futuros eventos dañosos. Sin perjuicio de ello y, como corolario en un diálogo de fuentes jurisdiccionales, se ha señalado desde hace tiempo que el «abuso de la libertad de expresión no puede ser objeto de medidas de control preventivo, sino con fundamento en la responsabilidad de quien lo haya cometido»."

Más allá de lo resuelto por los tribunales, bien vale relacionar los temas, al menos en abstracto, y luego ejemplificar supuestos en donde procede o no la adjudicación de responsabilidad. A este respecto, muchos tribunales han adoptado la teoría del riesgo por el riesgo mismo y, en otra opinión cercana, la teoría del riesgo generador de frutos.

Si bien en ambos casos la responsabilidad es objetiva, la teoría del riesgo por el riesgo mismo se sostiene con independencia del lucro que proporcione la actividad del intermediario y se centra directamente en la acción de intermediar como partícipe necesario de la infracción, entendiendo la intermediación como una actividad riesgosa. En otro orden, la teoría del riesgo generador de frutos, además de comprender la intermediación como presupuesto de responsabilidad, entiende que también debe encontrarse presente el resultado lucrativo que la actividad genera (publicidad arancelada, entre otros). Cabe preguntarse si estos presupuestos resultan suficientes

10. Hoy posible mayoría, al menos teniendo presente quienes continúan integrando el tribunal.

11. Opinión consultiva OC-5, Corte Interamericana de Derechos Humanos, serie A número 5, 13 de noviembre de 1985. 
para endilgar al intermediario responsabilidad por hechos de terceros que han utilizado sus servicios. Entiendo que no deben tomarse estas posturas ya receptadas por tribunales extranjeros tal y como se reseñara previamente, por cuanto, además de constituir soluciones injustas, también acarrean la consecuencia clara de acabar con la inversión en tecnología.

El motor de búsqueda es semejante a un nomenclador automático que presenta un sistema de reconocimiento y emparentado automatizado de sitios web. Estos intermediarios ponen a disposición del público mega bases de datos que registran los contenidos temáticos que circulan por internet, clasificándolos para una averiguación clara y eficaz y vinculándolos mediante enlaces (Lipszyc, 2004: 361). Es por ello que la responsabilidad objetiva no resulta atribuible y el lucro o beneficio por la actividad de intermediar no es suficiente. El lucro constituye una consecuencia de la actividad, pero primero debemos atender a si esa actividad, en sí misma, acarrea responsabilidad por el sólo hecho de tener lugar. Ya se ha dicho que un razonamiento de este tipo no debe seguirse conforme las razones expuestas.

Por otro lado, están quienes adoptan la postura que entiendo correcta, la de analizar si existió una responsabilidad subjetiva que pueda encuadrarse en las acciones dolosas o culposas y, en torno a ello, aplicar sanciones de distinto tipo y alcance. Ello sin caer en el facilismo de exigir obligaciones de cumplimiento imposibles, como el monitoreo permanente, sino en la necesidad de interpelar a los intermediarios al establecimiento de medidas rápidas y efectivas de acción ante las denuncias de violaciones manifiestas que les sean notificadas. El agravante respecto de las infracciones en cuanto deben ser manifiestas, atiende a la necesidad de garantizar los derechos humanos de libertad de expresión y de información.

Es decir, que debe acreditarse una conducta al menos culposa por parte del intermediario para adjudicarle responsabilidad. Esta sanción tiene como fuente tanto la manipulación discrecional y animosa de la información por la causa que fuere (a cambio de pago por publicidad u otras prestaciones), como el no resolver las denuncias o no haber establecido mecanismos para que las mismas se produzcan y puedan ser tratadas en un plazo breve.

Finalmente, resulta una obviedad de que el intermediario, para salvar su responsabilidad, debe haber actuado con buena fe diligente. Esto último es no sólo desconocer la infracción, sino también haber agotado los buenos usos de un profesional en la materia para acceder al conocimiento en tiempo oportuno (De Miguel Asensio, 2015: 272). ${ }^{12}$ De no ser así, responderá en todo caso por su obrar negligente y culposo. Sin perjuicio de ello, es dable destacar que la jurisprudencia referida ha centrado su foco

12. La Directiva de Comercio Electrónico Europea, con buen criterio, sanciona al intermediario no sólo cuando tenga conocimiento efectivo, sino que es suficiente cuando tenga conocimiento de hechos o circunstancias por los que la actividad o información revele su carácter ilícito. 
en los derechos de imagen y no en los derechos de autor, por lo que es oportuno señalar que el fundamento de la libertad de expresión necesariamente debe ceder si el objeto del acto claramente reside en distribuir o comunicar obras protegidas.

\section{Medidas cautelares: Procedencia y extensión}

En otro orden, en lo que hace a la posibilidad del progreso de medidas cautelares (incluso aquellas autosatisfactivas) que tengan por destinatario a un buscador de internet y por objeto la temporaria supresión por éste de la accesibilidad o conexión con el sitio web, se han presentado criterios encontrados. Por un lado, se ha sostenido en ese campo que no debe proceder, conforme ha manifestado alguna jurisprudencia, «una medida que ordene al responsable de un motor de búsqueda de sitios de internet bloquear la información agraviante respecto del reclamante y la obligación de monitorear permanentemente la red para evitar que se reitere la conducta, puesto que su alcance tan general torna dificultosa, si no imposible, la verificación de su efectivo acatamiento, máxime cuando su cumplimiento involucra un medio altamente dinámico debido a los nuevos sitios que en forma permanente son incorporados, vulnerando además lo dispuesto en el artículo 1 de Ley 26.032».13

Como contrapartida, otro supuesto es aquél en el que la posibilidad de cumplir del intermediario es evidente, ya que este último es quien cuenta con las herramientas necesarias para hacer cesar y, eventualmente, reparar el perjuicio. ${ }^{14}$ Asimismo, existe consenso en que debe existir precisión en la denuncia de violación al derecho de autor, al identificar concretamente la página web (URL) en donde se produce el hecho, puesto que no basta remitir al sitio web en general. De lo contrario, se vulnera el bloque constitucional y legal que ampara la libertad de expresión, como garantía de investigar, buscar, recibir y difundir informaciones, opiniones e ideas de toda índole, sin consideración de fronteras y por cualquier medio, incluso los electrónicos. ${ }^{15}$

\section{La venta y la licencia del software: Situación argentina a la luz de la LPI y del nuevo Código Civil y Comercial}

La comercialización del software tiene lugar, mayormente, a través de su venta o el otorgamiento de una licencia de uso. Si bien sus particulares características lo hacen merecedor de un régimen particular, esta situación no ha sido observada por muchos

13. Sagües Guillermo Ernesto y otro c/ Google Inc. y otro s/ daños y perjuicios, Cámara Nacional de Apelaciones en lo Civil y Comercial Federal, sala 3, 13 de mayo de 2015, cita: MJ-JU-M-95026-AR, MJJ95026, MJJ95026.

14. N. E. F. con Facebook Argentina S.R.L. s/ medida autosatisfactiva, Juzgado Federal de Río Cuarto, 4 de septiembre de 2013, cita: MJ-JU-M-100549-AR.

15. S. M. con Google Inc. s/ medida cautelar autónoma, Cámara Federal de Mendoza, sala B, 2015. 
países, que le reconocen el carácter de obra protegida a raíz de los tratados ADPIC de la OMC y TODA de la OMPI.

Los convenios internacionales referidos han receptado el derecho de distribución y arrendamiento de los programas de computación, como así también han emplazado a los Estados firmantes a resguardar las medidas tecnológicas de protección que blindan estas obras a fin de evitar infracciones de terceros respecto de los derechos de autor o titularidad que pesan sobre aquéllas.

Por su parte, la falta de regulación diferenciada de estos objetos digitales ha llevado a la aplicación de normas cuyo espíritu ni remotamente las tuvo presente, por lo que las soluciones, salvo casos muy excepcionales, no son adecuadas. Máxime si se trata de normas imperativas, inderogables por las partes, por cuanto la autonomía de la voluntad no puede sustituir y superar el defecto legislativo. Esto ocurre en Argentina, pero, llamativamente, ha tenido lugar con la reciente sanción del nuevo Código, un cuerpo que tiene sus notas de modernidad pero que en esta materia, entiendo, ha errado; todo lo cual intentaré fundar a continuación.

\section{Sistema de prelación normativa en el Código Civil y Comercial}

Para el análisis del instituto cuya crisis planteamos, es precisa una radiografía del cuadro normativo aplicable y la prelación de preceptos en el orden aplicativo, ya que concurren normas de tipo especial, dispuestas por la Ley 11.723 (LPI) y del Código Civil y Comercial (CCCN).

En primer orden, es importante destacar que el nuevo cuerpo general civil y comercial nacional dispone un orden de aplicación normativa cuya observancia es insoslayable, al establecer que en materia contractual debe estarse a lo que resuelvan las normas imperativas de la ley especial y del Código como primera medida, luego a lo previsto por las partes en uso de la autonomía de la voluntad y, por último, a las normas supletorias.

La necesidad de revisar este sistema reside en que se ha dispuesto por el nuevo Código la extensión aplicativa de las normas reguladoras de los contratos de concesión, a los contratos de venta o comercialización del software o de procedimientos similares (artículo 1.511, inciso a de CCCN).

Así las cosas, en materia de venta de programas de computador no hay dudas de que debe estarse a lo dispuesto por las normas indisponibles de la ley especial y del nuevo Código respecto de la concesión, luego a lo previsto por las partes al contratar y, finalmente, a las normas supletorias de la ley especial y del nuevo Código, en ese orden. Por otro lado, el interrogante se plantea en relación al término comercialización y si éste incluye, o no, el contrato de licencia de uso, puesto que en el primer caso las consecuencias afectarían considerablemente la costumbre comercial. 
Aplicación a la comercialización del software de normas relativas al contrato de concesión

En primera medida, es dable criticar el término sajón (software) utilizado por el artículo 1.511, inciso a del CCCN, puesto que nuestra LPI ya había adoptado la denominación de esa obra protegida conforme su versión española, esto es los programas de computación. Existe, en este caso, reincidencia del error legislativo, ya que lo mismo se produjo con la sanción de la Ley 25.922 de la promoción de la industria del software.

En segundo lugar, la expresión «venta o comercialización», tomada en términos genéricos, no caben dudas de que incluye a las licencias de uso y cualquier otra forma de explotación, por lo que los alcances de la norma son superlativos. Si así fuera, no acordamos con aquella respetable doctrina que justifica la inclusión de este precepto bajo el argumento de que se habrían receptado contratos actuales sobre tecnología y hasta la fecha carentes de regulación (Rivera y Medina, 2014: 586), ya que el régimen especial de la Ley 11.723 había cumplido tal cometido mediante la reforma del año 1998 por la Ley 25.036 , acto por el cual se introdujo el artículo 55 bis. Más bien se ha venido a intervenir, de manera innecesaria, la autonomía de la voluntad.

A modo de prólogo, vale decir que, si bien la naturaleza de los programas de computador fue discutida previo a su inclusión en el derecho autoral, ello no implica que pueda agregarse, sin más, la explotación de estas obras en otro régimen con perfiles propios. El artículo 1.511 del CCCN, que aplica las normas de la concesión a la venta o comercialización de los programas de computación, resulta anacrónico y asistemático.

La problemática generada no es menor conforme el sistema de prelación normativa, puesto que preceptos indisponibles que atienden al contrato de concesión le serán aplicados a la explotación de los programas de computación. A modo de ejemplo, vale referir que en los contratos de venta o comercialización de software o procedimientos similares no podrá pactarse un plazo inferior a cuatro años de duración (salvo el supuesto excepcional de que el concedente provea del establecimiento al concesionario) y en caso de continuación de la relación, una vez cumplido el plazo pactado sin pactar uno nuevo, el plazo se convierte en indeterminado (artículo 1.505 de la CCCN); es necesaria, previa a la extinción del contrato con plazo indeterminado, activar un preaviso equivalente a un mes por cada año de vigencia del contrato, el que, en caso de omitirse, obliga a indemnizar las ganancias dejadas de percibir por ese período (artículos 1.508, 1.402 y 1.493); finalmente, se aplican las causales de resolución contractual previstas para el contrato de agencia como, por ejemplo, la disminución significativa del volumen de negocios del agente (artículos 1.509 y 1.494), etcétera.

En este orden de pensamiento, creemos que no debe incluirse a la licencia de uso dentro del género comercialización que prescribe el artículo 1.511 inciso a del CCCN, ello por los siguientes argumentos: 
- Desde una perspectiva sistemática, la norma se encuentra ubicada dentro de los capítulos del nuevo Código dedicados a los contratos de distribución, no de arrendamiento.

- La norma no refiere expresamente a los contratos de licencia, como sí lo hace respecto del contrato de venta, por lo que entendemos que al referirse a comercialización lo hace a otras formas de distribución.

- Sin otorgar ultraactividad al Código de Comercio derogado, pero sí tomándolo como fuente de interpretación del término comercialización, debemos atender al concepto tradicional de acto de comercio, consistente en la adquisición onerosa y en propiedad de una cosa o derecho sobre ella para lucrar con su enajenación, lo que no ocurre en el contrato de licencia (artículo 8 del Código de Comercio derogado).

- La costumbre en la contratación de licencias de uso sugiere la posibilidad de pactar plazos menores que el mínimo imperativo dispuesto para los contratos de concesión (cuatro años) en el nuevo Código.

- Asimismo, en absoluto al contrato de licencia de uso pueden serle aplicables las causales de resolución previstas para el contrato de agencia, por cuanto atienden a otras circunstancias y persiguen finalidades no extensibles a figuras ajenas a los contratos de distribución.

- Desde un criterio económico, de incluir a la licencia de uso en este régimen, se estaría perjudicando la inversión y comercialización del software en Argentina.

Sin perjuicio de estas razones, lo central del análisis deviene de que tanto el $\mathrm{AD}$ PIC en el ámbito de la OMC, cuanto el TDA administrado por la OMPI, ambos suscritos por Argentina y operativos por mandato constitucional (artículo 75 inciso 22), regulan los derechos de arrendamiento comercial y alquiler, respectivamente (artículos 11 de ADPIC y 7 de TODA). Atento a esa referencia es que se podría proponer la inclusión de la licencia de uso en el género comercialización, vocación que desde ya le negamos a ese contrato por lo antes mencionado.

Por lo expuesto, habrá de estarse en todo sentido a la interpretación de los tribunales respecto del conjunto de los preceptos referidos, ya que se ha venido a invadir por vía indirecta el terreno de la autonomía de la voluntad y el régimen especial que la misma reforma de 1998 había dejado a salvo a causa de las características particulares de estos objetos digitales protegidos por el derecho autoral. 


\section{Competencia jurisdiccional y legislación aplicable a los delitos contra la propiedad intelectual en internet}

La competencia jurisdiccional y la legislación aplicable son dos cuestiones de derecho internacional privado que toman necesaria relevancia en materia de infracciones cometidas a través de internet.

Sucede que, en la World Wide Web, las conductas tienen alcance universal. Sin perjuicio de ello, como ya se ha referido, quien sostiene que internet no tiene fronteras se equivoca, bien que las tiene y los servidores situados en diferentes países se ocupan, en casos puntuales, de procurar o impedir el acceso de usuarios a un determinado dominio.

Ingresando en el análisis propuesto, lo que nos interesa es responder sobre dónde puede el autor o titular reclamar la protección de los derechos sobre las obras que fueran vulnerados mediante conductas en red y qué legislación resulta rectora de los mismos.

El derecho argentino no contiene normativa específica al efecto, por lo que debemos estar al régimen general. Por el lado del derecho comparado, a fin de tenerlo presente por su avanzado tratamiento del asunto, la Unión Europea en materia de jurisdicción aplicable se adscribe a dos criterios, el del domicilio del demandado (artículo 4 de RB1) y el del lugar del daño (artículo 7.2 de RB1 bis).

En el primer caso (domicilio del demandado), conocido como fuero general, vale revisar para determinar la ley aplicable si se han producido daños en distintos territorios, ya que el juez competente puede aplicar cumulativamente sendos derechos según el sitio objeto de la infracción conforme al criterio de la lex loci protectionis, que informa el artículo octavo del Reglamento Roma II de la Unión Europea (Fernandez Rozas, De Miguel Asensio y Arenas García, 2015: 150). Ahora bien, para el segundo caso, es decir, la interposición de la acción ante los tribunales del país en donde se ha cometido el ilícito, la cuestión radica en determinar con precisión cuál sería el lugar del daño atento a lo complejo que resulta este tipo de acto cometido desde un escenario en línea. A este respecto, se ha dicho que puede adoptarse una interpretación alternativa del lugar del daño, comprensiva tanto del lugar de origen o transmisión como de manifestación del daño o recepción y siempre que ambos lugares protejan la obra en cuestión. ${ }^{16}$ Para este último supuesto, la competencia y ley aplicable es limitada, puesto que se reduce a entender sobre el daño puntual producido en el territorio del foro.

Seguidamente, como se señaló, en el caso argentino el asunto no presenta un tratamiento particular, por lo que se regirá conforme las disposiciones generales. Sin

16. Sentencia de Pez Hejduk con EnergieAgentur.NRW GmbH, Tribunal de Justicia de la Unión Europea, C-441/13, 22 de enero de 2015. Sentencia de Peter Pinckney con KDG Mediatech AG, Tribunal de Justicia de la Unión Europea, C-170/12, 3 de octubre de 2012. 
perjuicio de ello, bien vale tener presente lo expresado respecto de los criterios para resolver supuestos complejos (por ejemplo, la extensión de lugar del daño). Nuestro sistema atiende al criterio general del domicilio del demandado y lugar de producción del hecho dañoso, a elección del actor (artículo 5 inciso 4 de CCCN), teniendo en cuenta en el segundo caso que, mínimamente, el daño tendrá lugar en todo el territorio nacional si se utiliza un dominio geográfico (.ar) o, más aún, fuera del mismo, si se presentan y concurren otros factores a tener en cuenta como un dominio genérico (.com), el idioma del sitio web y los destinatarios de sus contenidos.

Asimismo, si las partes residen en una misma ciudad, serán competentes los tribunales ordinarios de la misma o, en caso contrario, si residen en diferentes provincias o incluso para el caso de que alguna de ellas lo haga en el extranjero, lo será la justicia nacional (artículo 2 inciso 2 de Ley 48). Por razones de economía y celeridad, resulta más beneficioso reclamar, cualquiera sea el criterio elegido, en donde el demandado disponga de bienes para su rápida ejecución.

Respecto del régimen rector sancionador de la infracción, entendemos que resulta de aplicación el criterio de la lex loci protectionis, puesto que la protección del derecho debe reclamarse conforme la tutela que ofrecen los diferentes sitios donde ha sido vulnerado. No hay que olvidarse de que se trata de derechos territoriales, por lo que, para el caso de residir el demandado en el extranjero y la demanda entablarse en nuestro país por constituir éste el lugar del daño, la misma deberá sólo ser revisada en materia de ese hecho particular y no de daños producidos en otros sitios.

En otro orden, si la contienda motivada por daños producidos en diversos países se presenta entre residentes nacionales y se entabla la acción ante el juez del domicilio de uno de ellos, el tribunal podrá entender sobre el conjunto de las conductas lesivas y aplicar cumulativamente los derechos protectorios correspondientes a cada lugar donde el daño se produjo.

El CCCN argentino, para estos supuestos en materia de responsabilidad civil, ha introducido preceptos que colaboran con el objetivo propuesto, todo a fin de resolver los problemas de jurisdicción competente y legislación aplicable. Así es que la jurisdicción estará encomendada al juez del domicilio del demandado, o bien a aquél en donde se produjo el hecho generador del daño o, asimismo, puede serlo también el magistrado del lugar donde el hecho ha producido sus efectos (artículo 2.656).

Asimismo, respecto al derecho aplicable, la normativa impone que sea el del lugar en donde se produce el daño, salvo que actor y demandado tengan domicilio en el mismo país al tiempo del perjuicio reclamado, supuesto en el que se aplica el derecho de ese país (artículo 2.657).

Finalmente, respecto del régimen establecido para contratos de consumo, la competencia jurisdiccional estará dada, a opción del consumidor, por el lugar de celebración del contrato, del cumplimiento de la prestación del servicio, de la entrega de bienes, del cumplimiento de la obligación de garantía, del domicilio del demandado o del 
lugar donde el consumidor realiza actos necesarios para la celebración del contrato. Asimismo, también son competentes los jueces del Estado donde el demandado tiene sucursal, agencia o cualquier forma de representación comercial, cuando éstas hayan intervenido en la celebración del contrato o cuando el demandado las haya mencionado a los efectos del cumplimiento de una garantía contractual. En otro orden, cuando el consumidor sea el sujeto pasivo de la acción, ésta deberá ser entablada ante los jueces del Estado del domicilio del consumidor, sin que se admita acuerdo de elección de foro (artículo 2.654). Por el lado del derecho aplicable, éste será el del país del domicilio del consumidor para los casos en que: la conclusión del contrato fue precedida de una oferta o de una publicidad o actividad realizada en el Estado del domicilio del consumidor y éste ha cumplido en él los actos necesarios para la conclusión del contrato; o el proveedor ha recibido el pedido en el Estado del domicilio del consumidor; o el consumidor fue inducido por su proveedor a desplazarse a un Estado extranjero a los fines de efectuar en él su pedido; o en el caso de los contratos de viaje, por un precio global, que comprenden prestaciones combinadas de transporte y alojamiento. Para el resto de los supuestos, los contratos de consumo se rigen por el derecho del país del lugar de cumplimiento. En caso de no poder determinarse el lugar de cumplimiento, el contrato se rige por el derecho del lugar de celebración (artículo 2.655).

\section{Delitos sobre los objetos digitales: Programas de computación y bases de datos}

El nuevo escenario de la sociedad de la información requiere de tipificaciones de conductas novedosas modificando los tipos delictivos existentes, a fin de lograr una inobjetable aplicación de los preceptos represivos. Asimismo, es necesaria una actualización no sólo legislativa, sino también técnica y jurisprudencial ajustada a la evolución de las nuevas tecnologías (Tobares Catalá y Castro Argüello, 2009: 119).

El artículo 183 del Código Penal argentino reprime con «prisión de quince días a un año, el que alterare, destruyere o inutilizare datos, documentos, programas o sistemas informáticos; o vendiere, distribuyere, hiciere circular o introdujere en un sistema informático, cualquier programa destinado a causar daños».

Con esta disposición se da cumplimiento, aunque en forma preliminar, a los compromisos asumidos por nuestro país en la suscripción de los Tratados Internet de la OMPI.

El tipo penal sanciona a quien, en forma directa, altera, destruye o inutiliza un programa de computación, como también a quienes incentivan estos actos por el expendio, distribución, circulación o introducción de programas cuya función es la producción de aquellos actos sancionados.

En este orden, para comprender el alcance del precepto debemos recalar en las medidas tecnológicas de protección instrumentadas para la protección de las obras 
digitalizadas, las cuales constituyen unas barreras tecnológicas frente al accionar de terceros infractores. Se ha dicho que son

toda técnica, dispositivo o componente que, en su funcionamiento normal, esté destinado a prevenir o impedir la violación de los derechos de autor o los derechos afines, el acceso a una obra o el uso de la misma sin autorización de los derechohabientes o de la ley (Garrote Fernández Díez, 2003: 505).

Las medidas tecnológicas protectoras resultan, mayormente, exitosas respecto del usuario común no especializado en tecnología, ya que con el experto en informática no suelen presentar la misma suerte y este último puede, con frecuencia, sortearlas $y$, asimismo, fabricar programas que tengan por objeto ese tipo de actos para posibilitar que otros obtengan el mismo resultado. Ambas conductas, la infracción directa o la intermediación necesaria para procurarla, se encuentran comprendidas y sancionadas por el tipo penal doméstico.

En el derecho comparado, se han advertido este tipo de reglas que no sólo sancionan la conducta infractora en sí misma, sino aquélla que la posibilita mediante la provisión de herramientas digitales cuya principal función está destinada a facilitar la acción dañosa. Así es como el Texto Refundido del Real Decreto Legislativo español de 1996, Ley de Propiedad Intelectual, establece en su artículo 102, inciso c, con ubicación sistemática en el apartado dedicado a los programas de ordenador, que,

a efectos del presente título y sin perjuicio de lo establecido en el artículo 100, tendrán la consideración de infractores de los derechos de autor quienes, sin autorización del titular de los mismos, realicen los actos previstos en el artículo 99 y en particular: $[\ldots]$ c) quienes pongan en circulación o tengan con fines comerciales cualquier instrumento cuyo único uso sea facilitar la supresión o neutralización no autorizadas de cualquier dispositivo técnico utilizado para proteger un programa de ordenador.

Esta regulación resulta consecuencia directa de la incorporación y transposición al derecho ibérico de la normativa comprendida en la directiva comunitaria europea sobre programas de ordenador (91/250/CEE).

\section{Conclusiones}

Por todo lo expuesto es que, habiendo realizado un análisis descriptivo de la legislación aplicable en materia de derecho de autor y derechos conexos, entendemos es imperiosa la necesidad de revisión del régimen autónomo argentino, por cuanto la realidad digital por su dinámica se ha distanciado de los preceptos que intentan brindar soluciones y esto repercute en la garantía de seguridad que debe imperar en el ejercicio de los derechos tutelados. Más allá de los aportes que realizan los convenios 
internacionales reseñados y que, sin perjuicio de su aplicación operativa, también han conducido a una leve actualización del derecho patrio, lo cierto es que estamos a más de veinte años de los Tratados Internet y a casi veinte años de la reforma introducida por la Ley 25.036, por lo que es innegable que deben implementarse nuevos preceptos para resolver nuevas realidades.

\section{Referencias}

CICOMRA, Cámara de Informática y Comunicaciones de la República Argentina (2016). Bases para una legislación de servicios TIC. Ente Nacional de Comunicaciones de Argentina. Disponible en http://bit.ly/2Di1Xjr.

De Miguel Asensio, Pedro (2015). Derecho privado de internet. Pamplona: Thomson Reuters.

Emery, Miguel Ángel (2014). Propiedad intelectual. Buenos Aires: Astrea.

ERdozain López, José Carlos (1997). Las retransmisiones por cable y el concepto de público en el derecho de autor. Pamplona: Aranzadi.

Fernandez Rozas, José Carlos, Pedro Alberto De Miguel Asensio y Rafael Arenas García (2015). Derechos de los negocios internacionales. Madrid: Iustel.

Garrote Fernández Díez, Ignacio (2003). El derecho de autor en internet. Granada: Comares.

Goldstein, Mabel (2005). El derecho de autor y la sociedad de la información. Buenos Aires: La Rocca.

Gómez Perals, Miguel (1999). La cesión de uso de los programas de ordenador. Madrid: Colex.

González de Alaiza Cardona, José Javier (2008). La copia privada. Granada: Comares.

Lipszyc, Delia (2004). Nuevos temas de derecho de autor y derechos conexos. Buenos Aires: Zavalía.

Rivera, Julio César y Graciela Medina (directores) (2014). Código Civil y Comercial comentado. Buenos Aires: La Ley.

Rodríguez TAPIA, José Miguel y Fernando Bondía Román (1997). Comentarios a la Ley de Propiedad Intelectual. Madrid: Civitas.

-. (2017). El derecho de autor en el nuevo milenio. Córdoba: Lerner.

Simensky, Melvin y Lanning BRYer (1994). The new role of intelectual property in comercial transactions. Nueva York: John Wiley \& Sons.

Tobares Catalá, Gabriel y Maximiliano Castro Argüello (2009). Delitos informáticos. Córdoba: Advocatus. 


\section{Sobre el autor}

José Pablo Sala Mercado es abogado y notario por la Universidad Blas Pascal, Córdoba, Argentina. Magíster en Derecho de los Negocios Internacionales por la Universidad Complutense de Madrid, España. Doctor en Derecho y Ciencias Sociales por la Universidad Nacional de Córdoba, Argentina. Profesor en la Universidad Nacional de Córdoba, en la Universidad Blas Pascal e investigador asociado al Departamento de Derecho Privado de la Escuela de Derecho de la Universidad Bernardo O’Higgins, Chile. Su correo electrónico es josesalamercado@yahoo.es. 


\title{
REVISTA CHILENA DE DERECHO Y TECNOLOGÍA
}

La Revista de Chilena de Derecho y Tecnología es una publicación académica semestral del Centro de Estudios en Derecho Informático de la Facultad de Derecho de la Universidad de Chile, que tiene por objeto difundir en la comunidad jurídica los elementos necesarios para analizar y comprender los alcances y efectos que el desarrollo tecnológico y cultural han producido en la sociedad, especialmente su impacto en la ciencia jurídica.

\author{
EDITOR GENERAL \\ Daniel Álvarez Valenzuela \\ (dalvarez@derecho.uchile.cl) \\ SITIO WEB \\ rchdt.uchile.cl \\ CORREO ELECTRÓNICO \\ rchdt@derecho.uchile.cl \\ LICENCIA DE ESTE ARTÍ́CULO \\ Creative Commons Atribución Compartir Igual 4.0 Internacional
}

\begin{abstract}
y
La edición de textos, el diseño editorial

y la conversión a formatos electrónicos de este artículo

estuvieron a cargo de Tipográfica

(www.tipografica.cl).
\end{abstract}

